\title{
The effects of social media marketing on sports by using sports videos on facebook and instagram to attract the peoples to watch more sports
}

\author{
Manzar Shabab Yousuf ${ }^{1}$, Dr. Akhter Nawaz Ganjera ${ }^{2}$ \\ Email:msy3455178841@gmail.com
}

Phone: +923455178841

\begin{abstract}
Background: Social media is most commonly used tool to share information these days. So, it is an effective way to approach the target population using social media hence it is becoming popular for promoting social media marketing. Visual content like videos is an effective way for delivering messages. So the researchers are aimed at finding the efficiency of the using visual content (videos) for social media marketing.

Methods: Standard questionnaire was designed, and a cross-sectional survey was conducted. 700 individuals were enrolled 456 males and 244 females. Data regarding study was obtained and then analyzed using SPSS.

Results: Current studies showed that most of the sample population prefer to watch a video. They provide the reasons such as it provides a clear message and removes confusions. It is time saving and fascinating for the viewers. Instagram and Facebook are more frequently used than any other medium.

Conclusion: From this study we may conclude that using videos for social media (Facebook and Instagram) marketing can attract people to watch more sports. One reason is that the Facebook and Instagram are easy to assess and very common in use these days. Moreover, video is easier to deliver the concepts clearly removing the confusions, and the main reason is that it saves the time of people and can effectively deliver the message than any other tool.
\end{abstract}

Key words: Social media; Sports; Visual content; videos; cross-sectional survey; Facebook; Instagram

\section{INTRODUCTION}

Nowadays sports teams and players are commonly using Social media as a channel to interact with supporters (Pedersen, Parks, Quarterman, \& Thibauh, 2010). There are various sorts of social media presently being employed by sports clubs to advertise their teams. Facebook is a tool to share messages, upload videos or photos, and advertise forthcoming occasions. Recognizing particular impulses for motivating sports supporters is a challenging task, various researchers and investigations have studied the agents to motivate the fans and presently, however, many attempts have been made to examine the effects of social media marketing on responses of fans for sports. Researchers have previously investigated following factors: performance (Sloan, 1989; Gantz, 1981; Zillman, Bryant, and Sapolsky, 1989); a supporter's feeling of association to a club or team which is recognized as "fanship"; the capability to communicate with different supporters and avoiding the sense of breach (Guttman, 1986; McPherson, 1975; Smith 1988; Sloan 1989 Wenner \& Gantz, 1989; Branscombe \& Wann, 1991, 1994).

Social media marketing is of prominent importance for games and sports clubs and is of most significance for colleges concerning their projects for players (Miloch, 2010). Nowadays various sports divisions have practiced social media marketing to enhance the enthusiasm of fans. For instance, the sports division of Mississippi State University. They originated a social-media marketing intended to develop the supporter engagement which raised public awareness, through the year 2011 the Egg Bowl game, conducted every year at Mississippi State University, and the team gained the top position with the hashtag \#HailState. This happened for the 1st time that a university or college organized a social-media marketing plan for a genuine sport (Laird, 2011). Social media is an important tool as it can communicate about the partnerships and opponents of a team or a sports club employing various approaches counting visual contents in social-media (e.g. photos or videos). Hence, the application of visual contents in social-media for example, Facebook and Instagram provide the teams and clubs a medium for advertising team identification utilizing optical approaches. The use of visual contents like videos is important for promoting a sports team or team connections and consequently team ownership. 
Moreover, the team and cub managers must have to establish a well-defined team portrait that covers different team affiliations and ideas to improve team performance. It has been examined by using social media team managers can develop links and can communicate with stakeholders (Watkins and Lewis, 2014). Though the raised fame of this visual-based communication through social media has prompted the researchers for observing the effects of these tools; However, inspecting sport and effectiveness of visual content especially videos for social media marketing is the least studied area yet, except a few who studied the self-advertisement on social media (Smith and Sanderson, 2014). So, the present study is aimed at evaluating that how social media (Facebook and Instagram) marketing can attract people for sports using videos.

\section{MATERIALS AND METHODS STUDY DESIGN}

First of all, the standard questionnaire was designed to obtain the information for analysis. Questions were designed in such a way that they were originally close ended but for convenience respondent was allowed to add additional information if needed. The questionnaire included the questions to assess the do's and don'ts for making an effective sports video. Moreover, it also assessed the effective medium for social media marketing of sports; Facebook or Instagram. Questions asked were about interest of the respondents, Increased Information about games and players, new information about games, type of sports, video on a specific game or mixed, as well as about time saving etc.

\section{DATA COLLECTION}

The study was conducted in the University of Lahore Punjab the province of Pakistan. We selected undergraduate students for our research. About 800 students were enrolled initially in the study among which 500 were males and 300 males. They were asked to fill the questionnaire honestly and were advised just to write what they exactly feel. Data from the participants providing insufficient information was not considered for further analysis. So, finally the data obtained from 700 participants ( 244 females 456 males) was processed for analysis. Then the data was systematically arranged to form a spread sheet on Microsoft Excel 2016.

The excel sheet was converted to SPSS and the further analysis was performed using SPSS (Statistical Package for Social Sciences version 25). Mean and standard error of mean was determined for quantitative variables i.e. the age of the participants. In case of qualitative variables frequencies were determined. For graphical representation of the data the graphs were plotted on Microsoft Excel 2016. On the basis of frequency relevant effectiveness of the asked phenomena used in video to attract more and more people towards sports. The difference between the efficiency of Facebook and Instagram for social media marketing of sports using videos assuming a value of 0.05 was considered as level of significance.

\section{RESULTS}

\section{Assessment of the Participants responses}

Study was performed on 700 adult participants, having an average age of $24.46 \pm 0.10$ years, ranging between 19 and 29 years. Participants responses using Chi square test $(\mathrm{p}<0.05)$ showed that interest for sports is highly associated with age of participants showing a maximum interest in between 19 to 25 years in adults (Figure 1) (Table 1 ).

\section{Type of Social media}

Participants were asked which of the social medium they prefer to use frequently, Facebook, Instagram or any other? Majority participants (58\%) preferred Instagram, 37\% were those preferring Facebook while only $5 \%$ participants preferred twitter. The difference between the popularity of the Facebook and Instagram was assessed applying Chi square test. A statistically significant difference $(\mathrm{p}<0.05)$ was observed between popularity of the two. Instagram was shown to be more popular among the youngsters. However, overall the results indicate that the Facebook and Instagram are the powerful sources for social media marketing as majority of the people are connected to these networks so it's an easier way to approach them (Figure 2) (Table 1).

\section{Increased Information about games and players}

The participants were asked whether they can get increased and valuable information about games and players by videos uploaded on the social media i.e. Instagram and Facebook. Most of the participants (87\%) responded "Yes" while about 13\% responded with "No"'. Which shows that by using videos for social media marketing is an essential feature to attract the people towards sports and games. Because when people have information about something they ultimately get interested to know more about that particular matter as in this case the sports and games (Figure 3) (Table 2). 


\section{Types of Sports}

Participants were also asked to tell that if they are provided with videos of different games; video for which game or kind of sports they would prefer to watch. They were provided with five specific answers but they were also allowed to mention if the sport they like was different. The response of the participants was as follows (Figure 4) (Table 2).

\section{Cricket $(44 \%)>$ Football $(25 \%)>$ Hockey $(18 \%)>$ Tennis $(10 \%)>$ Polo $(3 \%)$ \\ Video should be specific or general}

Linked to the above mentioned questions the participants were also asked what kind of video is most preferable; a video on a specific sport or game being uploaded after a month or a general video discussing various games including your favorite game being uploaded every week. Most of the participants $(91 \%)$ preferred the second option i.e. a general video discussing various games including their favorite game being uploaded every week. This result shows us that a video based on more than one games might be more attractive than a video containing only one game as the former may attract more people while the later will attract only a small group. Moreover, it also shows that a video being uploaded soon after previous one is also crucial to attract the audience (Figure 5) (Table 2).

\section{Video uploaded on FB/IG Vs a Story published in a magazine or newspaper}

Participants were asked that a video uploaded on Facebook and Instagram and a Story published in a magazine or newspaper contain same content which one will they prefer and why? Majority of the participants $(97 \%)$ responded that they will prefer the video. The most common reason given by the participants was that the social media either Facebook or Instagram are easily accessible for them as compared to that of magazines or newspaper and the watching a video is much more convenient than reading a story from paper (Figure 6) (Table 2).

\section{A written story uploaded on FB/IG Vs a Video uploaded on FB/IG}

Just after the above question participants were asked which would they prefer whether a video uploaded on Facebook and Instagram and a written story uploaded on Facebook and Instagram contain same content which one will they prefer and why? Again the majority of participants (92\%) supported the video. The most common reason observed was that the video makes the concepts clear and removes the confusions which are usually associated with the written texts which totally devoid of emotions and expression. Moreover, watching a video do not take much time and its duration is already determined, so it also saves the time. These results show that video is quite efficient and effective than any other tool to attract people towards the sports (Figure 7) (Table 2).

\section{DISCUSSION}

Results of current studies shows that using videos for social media marketing is an essential feature to attract the people towards sports and games. Because when people have information about something they ultimately get interested to know more about that particular matter as in this case the sports and games.

Everyone don't have sufficient knowledge about everything however by watching videos they may gain at least some of information which they will surely share by which a network of communication may generate leading to attract more and more people towards sports (Thackeray et al., 2008).

Previously, it was very challenging for the sports club to efficiently interact with members. With the development of social media, now it is possible for team managers for updating and communicating to the athletes to provide valuable knowledge daily and to involve in a personal and effective communication (Abeza and Norm, 2013).

Using Social media smartly helps the traders to efficiently permits marketers to effectively involve and attract consumers to actively participate in concretion of goods and facilities that consequently raises brand variety (Miller \& Lammas, 2010; Harridge and Quinton, 2009). Mutually, these chances permit traders to create the feeling of satisfaction in customers such that they assume themselves as a member of that specific eventually retain trust in their brand (Harridge-March \& Quinton, 2009; Miller \& Lammas, 2010).

This result shows us that a video based on more than one games might be more attractive than a video containing only one game as the former may attract more people while the later will attract only a small group. Moreover, it also shows that a video being uploaded soon after previous one is also crucial to attract the audience. It is very important to keep the consumers updated. These results are consistent with the previous studies.

Sports customers' commitment and dedication are considerably robust than the commitment of consumers of other sectors (Waters, Burke, Jackson, \& Buning, 2010). Sports team fans eagerly and constantly demand fresh, proceeding, and off-the-ground news regarding their team they like. With this respect, social media is becoming a major tool to instantly interact with the fans and team supporters to 
keep them updated (Williams \& Chinn, 2010). Social media is an active and efficient tool to interact and communicate with and allow the supporters to express their sentimental responses (Constantinides \& Fountain, 2008). It improves the quality of communication and makes it easier to reach the consumer quickly (Hennig-Thurau et al., 2010; Ioakimidis, 2010).

Current studies showed that the most of the people prefer watching a video than written text either in print media or on the Facebook or Instagram. The most common reason given by the participants was that the social media either Facebook or Instagram are easily accessible for them as compared to that of magazines or newspaper and the watching a video is much more convenient than reading a story from paper. Moreover, they claimed that the video makes the concepts clear and removes the confusions which are usually associated with the written texts which totally devoid of emotions and expression. Furthermore, watching a video do not take much time and its duration is already determined, so it also saves the time. These results show that video is quite efficient and effective than any other tool to attract people towards the sports.

Our results are in line with previous works. For example, one of the studies conducted earlier suggested that the viewer's prefer strongly to watch a video than a written text containing exactly the same content. As video response assists the viewers to develop an individual link with the brand or organization and it helps to augment their interest for the sports the brand is aimed to advertise (Hilton and Rague, 2015).

The use of social media based on visual contents such as photos and videos is growing rapidly on social media sites (McNely, 2012). Amongst the increasing representation of these sites is Instagram, a video and images uploading place that enables a person to upload images or videos, plus to discuss and like images and videos of different people. Pew Research Center identified that the Instagram usage enhanced remarkably in from year 2014 amongst all chief demographic societies (Duggan, Ellison, Lampe, Lenhart, \& Madden, 2015). Approximately \% of adult internet users (18-29 years) are using Instagram (Duggan et al., 2015). Instagram is one of the most extensively used social media sites amongst university scholars, usually greater than those of Facebook and Twitter (Salomon, 2013; Clavio \& Walsh, 2013).

\section{CONCLUSION}

From this study we may conclude that using videos for social media (Facebook and Instagram) marketing can attract people to watch more sports. One reason is that the Facebook and Instagram are easy to assess and very common in use these days. Moreover, video is easier to deliver the concepts clearly removing the confusions, and the main reason is that it saves the time of people and can effectively deliver the message than any other tool. To effectively promote the social media marketing to attract the people for sports the organizations, brands and players need to assume the reason why people get attracted toward a specific kind of social media and which kind of visual content. They must focus on the types of sports, length of video, making a video which can attract everyone. Videos must be uploaded with a short gap to keep the fans or consumers updated about upcoming events to attract them to watch the sports.
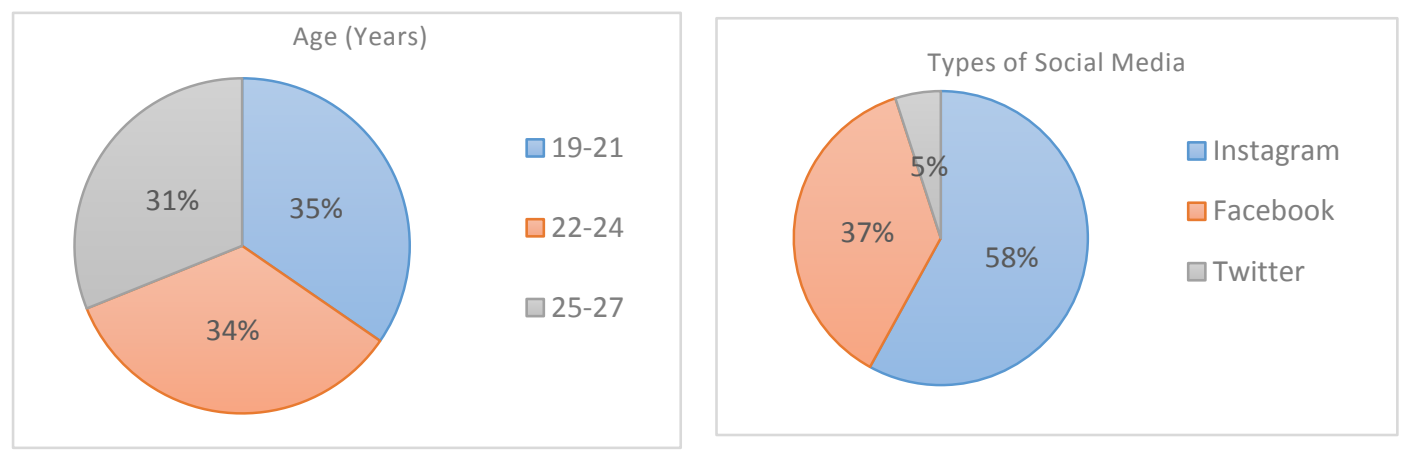


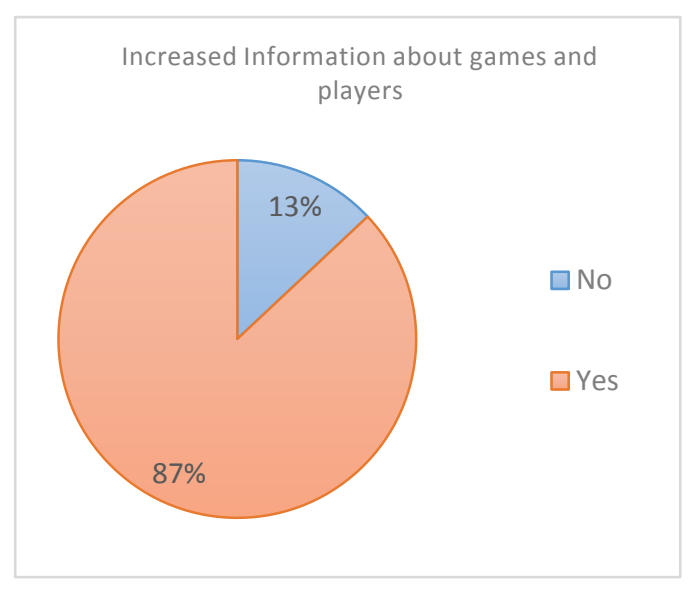

Figure 3

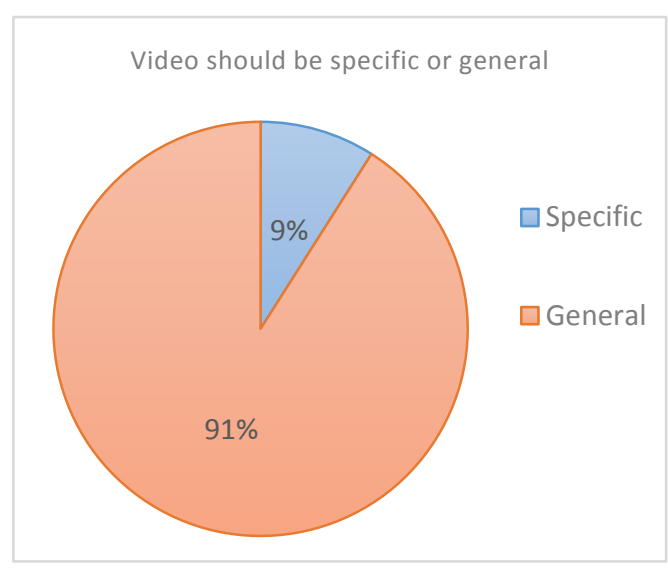

Figure 5

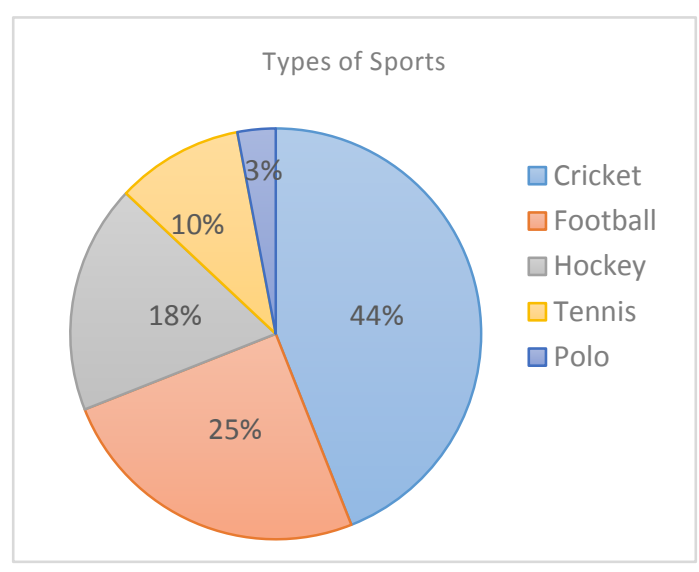

Figure 4

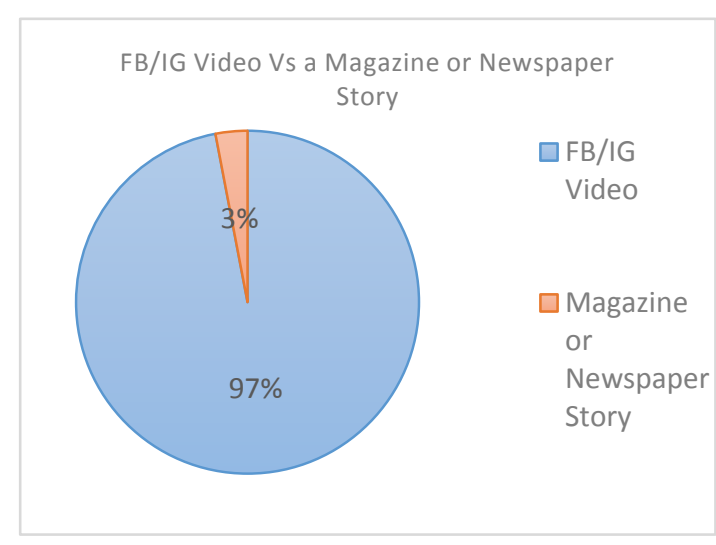

Figure 6

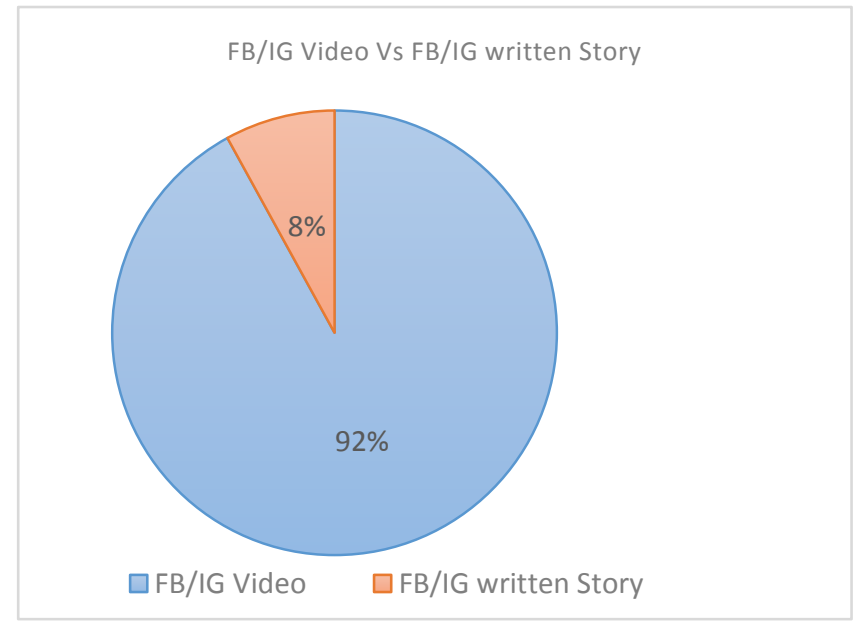

Figure 7 
Table 1: Results from Chi Square Test $(\chi 2$-test)

\begin{tabular}{|l|l|l|c|}
\hline Parameters & Range/Group & Frequency(\%) & P value $(\boldsymbol{\chi 2}$-test) \\
\hline Age (Years) & $19-21$ & 34.6 & 0.47 \\
& $22-24$ & 34.3 & \\
& $25-27$ & 31.1 & \\
\hline Types of Social Media & Instagram & 58 & 0.21 \\
& Facebook & 37 & \\
& Twitter & 5 & \\
& & & \\
\hline
\end{tabular}

*Significant $\mathrm{p} \leq \mathbf{0 . 0 5}$

Table 2: Frequency Distribution of Different Parameters in Studied Population

\begin{tabular}{|l|l|l|}
\hline Parameters & Range/Group & Frequency(\%) \\
\hline $\begin{array}{l}\text { Increased Information about } \\
\text { games and players }\end{array}$ & No & $13 \%$ \\
& Yes & $87 \%$ \\
& & \\
\hline Types of Sports & Cricket & $44 \%$ \\
& Football & $25 \%$ \\
& Hockey & $18 \%$ \\
& Tennis & $10 \%$ \\
& Polo & $3 \%$ \\
\hline Video should be specific or \\
general & & \\
\hline FB/IG Video Vs a & Specific & $09 \%$ \\
Magazine or Newspaper & General & $91 \%$ \\
Story & Magazine or Newspaper & $97 \%$ \\
& Story & \\
\hline FB/IG Video Vs FB/IG & & \\
written Story & FB/IG Video & $92 \%$ \\
& FB/IG written Story & $08 \%$ \\
\hline
\end{tabular}

\section{REFERENCES}

1. Pedersen, P., Parks, J., Quarterman, J., Thibault, L., (2010). Contemporary sport management (4th ed.). Champaign, IL: Human Kinetics.

2. Sloan, L R. (1989). The motives of sport fans. In J. H. Goldstein (Ed.), Sports, games, and play: Social and psychological viewpoints (2nd ed., pp. 175-240). Hillsdale, NJ: Lawrence Erlbaum.

3. Gantz, W. (1981). An exploration of viewing motives and behaviors associated with television sports. Journai of Broadcasting, 25, 263-275.

4. Zillman, D., Bryant, I., \& Sapolsky, B. S. (1989). Enjoyment from sports spectatorship. In J. H. Goldstein (Ed.), Sports, games, and play: Social and psychological viewpoints (2nd ed., pp. 241278). Hillsdale, NJ: Lawrence Erlbaum.

5. Guttman, A. (1986). Sports spectators. New York, NY: Columbia University Press.

6. McPherson, B. (1975). Sport consumption and the economics of consumerism. In D. W. Ball \& J. W. Loy (Eds.), Sport and social order: Contributions to the sociology of sport. Reading, MA: Addison-Wesley.

7. Smith, G. J. (1988). The noble sports fan. Journal of Sport \& Social Issues, 12, 54-65. 
8. Branscombe, N. R., \& Wann, D. L. (1991). Role of identification with a group, arousal, categorization processes, and self-esteem in sport spectator aggression. Human Relations, 45, 1013-1033.

9. Branscombe, N. R., \& Wann, D. L. (1994). Sport psychology. In F. N. Magill (Ed.), Survey of social science: Psychology Series (pp. 263-268). Pasadena, CA: Salem.

10. Miloch, K. (2010). Introduction to branding. In J.W. Lee (Ed.), Branded: Branding in sport business (pp. 3-9). Durham, NC: Carolina Academic Press.

11. Watkins, B., \& Lewis, R. (2014a). Initiating dialogue on social media: An investigation of athletes' uses of dialogic principles and structural features of Twitter. Public Relations Review, 40, 853-855.

12. Laird, S. (2011). First football endzone hashtag touches down in Mississippi. Mashable-The Social Media Guide.

13. Thackeray, R., Neiger, B., Hanson, C., \& McKenzie, J. (2008). Enhancing promotional strategies within social marketing programs: Use of Web 2.0 social media. Health Promotion Practice, 9(4), 338-343.

14. Miller, R., \& Lammas, N. (2010). Social media and its implications for viral marketing. Asia Pacific Public Relations Journal, 11(1), 1-9.

15. Harridge-March, S., \& Quinton, S. (2009). Virtual snakes and ladders: Social networks and the relationship marketing loyalty ladder. Marketing Review, 9(2), 171-181.

16. Waters, R., Burke, K., Jackson, Z., \& Buning, J. (2010). Using stewardship to cultivate fandom online: Comparing how National Football League teams use their Web Sites and Facebook to engage their fans. International Journal of Sport Communication, 4(2), 163-177.

17. Williams, J., \& Chinn, S.J. (2010). Meeting relationship-marketing goals through social media: A conceptual model for sport marketers. International Journal of Sport Communication, 3(4), $422-437$.

18. Hennig-Thurau, T., Malthouse, E.C., Friege, C., Gensler, S., Lobschat, L., Rangaswamy, A., \& Skiera, B. (2010). The impact of new media on customer relationships. Journal of Service Research, 13(3), 311-330.

19. Ioakimidis, M. (2010). Online marketing of professional sports clubs: Engaging fans on a new playing field. International Journal of Sports Marketing \& Sponsorship, 11(4), 271-282.

20. Duggan, M., Ellison, N. B., Lampe, C., Lenhart, A., \& Madden, M. (2015). Social media update 2014. Pew research center, 19.

21. Salomon, D. (2013). Moving on from Facebook. Using Instagram to connect with undergraduates and engage in teaching and learning. College \& Research Libraries News, 74(8), 408-412.

22. Clavio, G., \& Walsh, P. (2013). Dimension of social media utilization among college sports fans. Communication \& Sport, 2(3), 261-281.

23. McNely, B. J. (2012, October). Shaping organizational image-power through images: Case histories of Instagram. In 2012 IEEE International Professional Communication Conference (pp. 1-8). IEEE.

24. Smith, L.R., \& Sanderson, J. (2014, August). I'm going to Instagram it! An analysis of athlete self-presentation on Instagram. Poster session presented at the meeting of the Association for Education in Journalism and Mass Communication, Montreal, Canada.

25. Hilton, S., \& Rague, B. (2015, October). Is video feedback more effective than written feedback? In 2015 IEEE Frontiers in Education Conference (FIE) (pp. 1-6). IEEE.

26. Constantinides, E., \& Fountain, S. (2008). Web 2.0: Conceptual foundations and marketing issues. Journal of Direct Data and Digital Marketing Practice, 9(3), 231-244. 